\title{
The associations between conceptual learning, physics identity and social interdependence
}

\author{
Miguel Rodriguez and Geoff Potvin \\ Department of Physics and STEM Transformation Institute, Florida International University, 11200 SW $8^{\text {th }}$ Street, Miami, FL 33199
}

This study was conducted in a Modeling Instruction Introductory Physics I course and investigates whether students' social interdependence is associated to semester-long conceptual and physics identity gains. In Modeling Instruction, students spend the majority of class time working in small groups leading to varying levels of task and outcome interdependence with other group members. Detailed data were collected to measure pre- to post- conceptual learning and identity gains as well as reported task and outcome interdependence for each student. Students' pre-semester individualism and cooperation beliefs were also collected as these measures have been shown to be correlated with social interdependence. Linear regressions were conducted to understand associations between interdependence measures and pre-to-post semester differences in students' conceptual and physics identity measures; notably, students who reported greater levels of initiated task interdependence also had more positive improvements in their beliefs in being recognized as a physics person. A significant positive shift in student's pre-to-post semester cooperation beliefs was also observed.

\footnotetext{
2020 PERC Proceedings edited by Wolf, Bennett, and Frank; Peer-reviewed, doi.org/10.1119/perc.2020.pr.Rodriguez Published by the American Association of Physics Teachers under a Creative Commons Attribution 4.0 license. Further distribution must maintain the cover page and attribution to the article's authors.
} 


\section{INTRODUCTION}

There is a growing demand for STEM majors in the United States as technology continues to be integrated into ever more facets of society, and to maintain a globallycompetitive high tech economy [1]. Low-quality early STEM courses are a leading cause of students switching out of science majors [2]. Student-centered instruction, such as that embodied through classrooms that rely on learning in small groups, has been repeatedly found to support students' learning more effectively than teacher-centered instructional methods [3]. To study one such environment that relies on small-group learning in detail, in this paper we use the lens of social interdependence theory because it lends itself to understanding successful group cooperation. We also use science identity theory, which has been found to predict students' science-related career choices [4,5]. It is desirable to identify particular classroom features that support students' identity development, which has been relatively understudied by comparison to studies of practices that impact students' conceptual learning $[6,7]$.

In this paper, data were collected from a single first semester university, Modeling Instruction introductory physics I (mechanics) class in order to model how student engagement in groups. The course consisted of students of varying majors which came from diverse backgrounds. Using the lens of social interdependence theory we analyzed both conceptual learning and physics identity outcomes. Modeling instruction is a well-established instructional design that involves regular small-group learning in which students build consistent scientific models. It utilizes several different representations (e.g. velocity graphs, force body diagrams, energy representations, etc.) to build models that explain a wide class of physical phenomena [8]. The implementation of frequent small-group work in Modeling Instruction provides an opportunity to study the interdependence of students as they learn in groups. The research questions driving this paper is:

- How is social interdependence associated with gains in conceptual understanding and physics identity outcomes? Particularly task and outcome interdependence experienced by students in smallgroup learning contexts.

- Did cooperation and individualism beliefs change over the course of the semester for our sample?

\section{BACKGROUND}

Positive social interdependence (SI) is associated to, and has a reciprocal relationship with: positive relationships, improved effort to achieve and improved social competence [9]. In general, social interdependence exists when individuals, in a group, are affected by the actions of others. The various forms of interdependence that have been identified include "task" and "outcome" interdependencies. For this study, task and outcome interdependence were measured, because our focus is on how students' depend on each other to achieve the learning tasks they are given in class and how this leads to group outcomes. Task interdependence is associated to the roles students play in a group and how they coordinate requirements between group members $[10,11]$. Outcome interdependence assesses how students' learning outcomes depended on their cooperation. When outcome interdependence is strong, groups perform better, as each group member's outcome depends on the groups' performance [12].

In addition to interdependence, as outcomes to this study, conceptual learning and physics identity gains were assessed. The former was assessed using pre- and postsemester measures of the Force and Motion Conceptual Evaluation (FMCE) [13], while the latter was assessed using a previous-developed physics identity instrument [5]. The change in students' FMCE scores provide a proxy for how well students learned mechanics during the semester, while the pre-to-post change in the physics identity measure informs if a student's recognition beliefs in physics, physics interests in physics, and/or performance/competence beliefs changed during the course. Data were also collected on students' pre-semester cooperation and individualism attitudes, which have been shown to be predictive of SI $[14,15]$.

\section{SURVEY DATA \& ANALYSIS}

In this paper, we report on a quantitative analysis that was conducted using multiple measures of students' SI and pre-semester beliefs to predict changes in physics identity and conceptual learning during a first-semester physics course using Modeling Instruction. There were 90 students enrolled in the course of study and, at any given time, 15 groups of 5-6 students were assigned by the instructor (6 different group arrangements during the semester). In total, data were collected on eight separate occasions: presemester, post-semester, and immediately after each group assignment ended. Surveys $1 \& 8$ included the FMCE [13], physics identity [5], SI and collective orientation scales $[14,15]$. In the other surveys (Surveys 2-7) task and outcome interdependence [16] were measured for students for each group they were a part of during the semester, immediately after each group assignment ended. All instruments used had been developed separately and there existed validity evidence for each $[15,16,17]$ but exploratory factor analyses were performed in some cases to assess elements of construct validity.

\section{A. Preliminary Analysis}

Surveys $1 \& 8$ utilized the social interdependence scale [15] and the collective orientation scale [16] together to 
predict the SI of students. Although the scale of Johnson \& Norem-Hebeisen was validated, the work was published in 1979. To complement this scale a collective orientation scale [16] was also used, to provide a more recentlyvalidated scale that also has been found to correlate positively with SI while predicting team performance. An exploratory factor analysis (EFA) was conducted on both these scales, which resulted in combining items from both. This EFA helped establish the relationship between both of these prior instruments, and to generate a prediction of the pre-semester propensity for interdependence of each student. The best fit for the EFA was found to be a twofactor solution. Items that did not load strongly to either factor were cut, and then the final EFA was constructed. The resulting factors were labeled "cooperation" and "individualism" beliefs. An important note here is that cooperation and individualism beliefs were loaded as two independent factors, as opposed to appearing as opposite extremes of each other. Instead, these beliefs exist somewhat independently of one another. Since cooperation is similar to collectivism, this is reminiscent to prior findings on individualism and collectivism beliefs [17]. In the end, these factors were used to generate a score measuring students' pre-semester cooperation and individualism beliefs.

In Surveys 2-7, students were asked to self-report on their task and outcome interdependence for the student groups they had just been a part of during each 2-3 week period in the semester, for six in total. To assess these constructs, items developed in prior research were used to measure task and outcome interdependence [17]. This earlier research originally intended to measure these outcomes in a work setting, so for the current study the items were adapted for an academic setting by changing "colleagues" to "group" to fit into the context. Van Der Vegt split the questions measuring task interdependence into two: initiated and received task interdependence. Splitting task interdependence allows for gauging the degree at which each student reported initiated tasks and/or whether the tasks were initiated by other group members (received task interdependence). Initiated task interdependence is a measure of how much a student felt the groups of a particular respondent needed information, help and work done from them. Received task interdependence, on the other hand, asked individual students how much they depended on their group for information, help and work. The task interdependence measures used 7 point anchored scales ranging from "Not at all" to "Very much." Next, outcome interdependence measures how students felt their groups impacted their success. This included asking if their group benefited or hindered them, whether they felt the group to be compatible or incompatible to them, if the group's success led to their own success and if the group's concerns matched their own. Outcome interdependence was also measured using 7 point anchored scales but each item had unique anchors.
Thus, there were three dimensions of interdependence assessed in Surveys 2 through 7: initiated task, received task and outcome interdependence. The items were assessed for construct validity by again using EFA, to test that items loaded as intended. The final EFA found consistent loadings onto these three factors. Following the EFA, scores were created for the three factors for each of the six rounds of survey. Then, the mean for each student (and each construct) was calculated to establish an average for students' reported initiated task, received task and outcome interdependence over the semester.

\section{B. Validating Predictive Measures for SI}

Further validation of the surveys was conducted by relating the cooperation and individualism beliefs from Survey 1 to the outcome and task interdependence from Surveys 2-7, since a priori these measures should be correlated. It was found that pre-semester cooperation beliefs were indeed predictive of the outcome interdependence of groups $(p<0.01)$. Table I shows the result of regressing outcome interdependence on presemester cooperation beliefs. This means that students with higher pre-semester cooperation beliefs reported that being in groups was more beneficial, on average, to succeeding in learning tasks. This is a confirmatory validation; it should be noted that these separate measures are from different literature bases and had not been previously crossvalidated. No significant correlations between pre-semester individualism beliefs to outcome interdependence were found. There was also no significant correlation found between pre-semester cooperation and individualism beliefs to task interdependence.

TABLE I: Regression model of cooperation beliefs on outcome interdependence

\begin{tabular}{lcccc}
\hline \hline & Estimate & Std. Error & $\mathrm{Z}$ value & \\
$\begin{array}{l}\text { (Intercept) } \\
\begin{array}{l}\text { Cooperation } \\
\text { beliefs }(\mathrm{N}=90)\end{array}\end{array}$ & 0.609 & 0.094 & 6.48 & $* * *$ \\
\hline \hline$* * * \mathrm{p}<0.001, * * \mathrm{p}<0.01, * \mathrm{p}<0.05$. Adjusted $\mathrm{R}^{2}=0.09$
\end{tabular}

\section{Analytical Methods for Results}

Using social interdependence, FMCE, physics identity, and pre-semester cooperation and individualism beliefs measures, linear regression models were (separately) constructed to test for associations between task/outcome interdependence with gains in conceptual understanding or physics identity. By matching students' pre-to-post semester surveys, the change in both FMCE responses and physics identity could be calculated. To account for nonresponses (particularly since the same students were being surveyed on eight different instances), multiple imputation 
was conducted using the $\mathrm{R}$ package Amelia [18]. Multiple imputation is a best-practices approach to maximize statistical power and reduce statistical biasing due to nonresponse, which was about $16 \%$ in the current data. Multiple imputation allows the researcher to preserve statistical power by accounting for missing responses, and is significantly favored over the common practice of listwise deletion. In the current analysis, one hundred independent imputations were conducted after which the package Zelig was used to construct and summarize the linear regression analysis using Rubin's rule [19,20].

\section{RESULTS}

\section{A. Associations Between Task Interdependence and Physics Identity}

The results of the regression models significantly predicting identity constructs are summarized in Tables II and III. The average initiated task interdependence positively predicts semester long standardized gains in physics recognition beliefs and performance/competence beliefs. Other interdependence measures were not found to be predictive of physics identity gains. That is, the model appearing in Table II shows that students who reported that their groups were more dependent on them for support, on average, over the semester had higher gains in recognition beliefs, a critical component of physics identity development $(p<0.01)$. The effect size is relatively large: a student reporting at the high end of the initiated task interdependence scale had a 0.509 (standardized to be out of a maximum of 1.000) greater gain in recognition beliefs than those at the low end. Those with lowest initiated tasks interdependence saw losses in their recognition beliefs, as indicated by an intercept of -0.279 . It seems reasonable that if students feel their groups relied on them during the learning physics topics, they had more opportunities to grow in their feelings of recognition in physics contexts.

Table II: Regression model of initiated task interdependence on gains in recognition beliefs

\begin{tabular}{|l|c|c|c|c|}
\hline \hline & Estimate & Std. Error & Z value & \\
\hline (Intercept) & -0.279 & 0.12 & -2.32 & $*$ \\
\hline $\begin{array}{l}\text { Initialized Task } \\
\text { Interdependence } \\
(\mathrm{N}=90)\end{array}$ & 0.509 & 0.176 & 2.89 & $* *$ \\
\hline \hline$* * \mathrm{p}<0.001, * * \mathrm{p}$ & & & & \\
\hline \hline
\end{tabular}

Similarly, there is a positive association between initiated task interdependence and gains in students' performance/competence beliefs (Table III). Again, students who reported they were the source of task initiation had greater gains in performance/competence beliefs $(\mathrm{p}<0.01$, estimated coefficient is 0.358$)$. Students who reported the lowest initiated task interdependence saw loses in their performance/competence beliefs as indicated by an intercept of -0.188 . Students who feel they have greater experience developing their ideas within their groups may have greater opportunity to build their performance/competence beliefs.

TABLE III: Regression model of initiated task interdependence on gains in performance/competence beliefs

\begin{tabular}{lcccc}
\hline \hline & Estimate & Std. Error & $\mathrm{Z}$ value & \\
(Intercept) & -0.188 & 0.083 & -2.27 & $*$ \\
$\begin{array}{l}\text { Initialized Task } \\
\text { Interdependence }\end{array}$ & 0.358 & 0.121 & 2.95 & $* *$ \\
$(\mathrm{~N}=90)$ & & & \\
\hline$* * * \mathrm{p}<0.001, * * \mathrm{p}<0.01, * \mathrm{p}<0.05$. Adjusted $\mathrm{R}^{2}=0.09$
\end{tabular}

These simple linear regression models were extended to include pre-semester cooperation beliefs as a second predictor. This was done to check the alternative hypothesis that students who initially showed greater cooperation beliefs were simply reporting higher task interdependence and also experienced greater gains in physics identity. In fact, adding cooperation beliefs to each model was not significant and so it did not confound the main finding of each model. In other words, incorporating prior cooperation beliefs did not qualitatively change the effect size nor the statistical significance of the association between initiated task interdependence and physics identity gains. Also, no significant association between physics interests and task interdependence (initiated or received) or outcome interdependence were found. Received task interdependence and outcome interdependence were not significant in any identity regression model.

\section{B. Associations Between Interdependence and Conceptual Learning}

Similarly, regression models predicting conceptual learning gains (post-FMCE minus pre-FMCE) were constructed using task/outcome interdependence as predictor variables. It was hypothesized, similar to other research [12,21], that students who reported higher levels of task or outcome interdependence would also display greater gains in learning gain. In fact, no significant associations were found. A borderline significant association was identified between learning gains and received task interdependence (and it was, in fact, a negative association); however, this was slightly above our alpha cutoff (of 5\%) and so is not considered a statistically significant finding. This non result may be due to the inherent complexity in the learning environment and in performing the physics tasks on the FMCE, or may be a reflection of the relatively small sample size in this work $(\mathrm{N}=90)$. 


\section{Change in Cooperation Beliefs over the Semester}

Having measures for cooperation and individualism beliefs made it possible to assess how these attitudes changed over the semester. Comparisons of the pre- to post-semester cooperation and individualism beliefs were conducted. For the former, there was a small effect size of 0.25 (95\% confidence interval: 0.07 to 0.59 ) and, for the latter, a negligible effect size of 0.17 (95\% confidence interval: -0.17 to 0.52 ). That is, this shows that cooperation beliefs improved over the semester, while individualism beliefs were not significantly affected. This may imply that the group experiences students had during class somewhat increased their attitudes towards working cooperatively. On the other hand, the semester did not increase or decrease their beliefs towards working individually.

\section{DISCUSSION}

These results suggest that students who initiate tasks with other group members more often have improved gains in their physics recognition and performance/competence beliefs. Thus, student participation in a small-group setting may be an essential way to support physics identity growth. Regularly initiating group tasks may allow students to be seen as good physics students by their peers and be associated with understanding and performing physics well. This adds to arguments in favor of the use of studentcentered classrooms in which students get more frequent opportunities to engage in group tasks. Through group work, students may come to see themselves and feel others see them as physics people (recognition beliefs), and to build their beliefs in their ability to be successful in physics (performance/competence beliefs). Out of the three subconstructs, recognition beliefs have been shown in other work to be particularly important to developing a physics identity and, consequently, for making physics-related career choices $[22,23]$. These results resonate with other research, such as earlier work that identified that selfefficacy beliefs (somewhat akin to, although distinct from, performance/competence beliefs), improves more in a Modeling Instruction context compared to traditional instruction [24].

For those interested in addressing the problem of low physics participation, engagement, and production of STEM professionals, these findings lend weight to those who would advocate for student-centered instruction based around small-group work; for example, Modeling Instruction. Other well developed pedagogies, such as Peer Instruction and SCALE-UP, may also contribute similar benefits to students' learning due to their regular reliance on small-group learning.

The final result found changes in student's cooperation beliefs from the beginning to the end of the semester. This suggests that students' preferences towards working in groups increased because of their experiences during the semester. This is significant because cooperation beliefs may be beneficial to students' professional careers. As technology evolves, teamwork and collaborations are becoming more regular features in science and engineering. This has led to employers seeking out individuals who have the ability to work in a team, making it a valuable asset [25]. Also as globalization increases, global collaboration is becoming more common, emphasizing the value of this disposition even more [26]. Besides enhancing professional cooperation, collectivist ideas have also been correlated to good citizenship behavior [27] and environmental beliefs [28] among other broader topics that are beyond the scope of this work.

The non-significant findings in this study are also worthy of reflection. For example, cooperation beliefs are predictive of the outcome interdependence students reported having in their groups. However, cooperation beliefs did not correlate with initiated task interdependence, meaning that students' participation was not determined (at least in this respect) by these pre-semester beliefs. This means there is a real opportunity for instructors and educators to scaffold/stimulate this type of activity in their classroom which, as seen in the results, is of benefit to students' developing physics identities. Also no significant association between cooperation or individualism beliefs and conceptual gains were found. This is consistent with the lack of other literature tying communal beliefs to academic performance. This may mean that students have an equal chance to increase their conceptual gains in Modeling Instruction regardless of their incoming attitudes on cooperation and individualism.

A limitation in this study is the statistical power and limited representativeness of the sample. The data used in this study were collected from a single class of 90 students, and this was both a technical limitation (restricting the complexity of models that could be constructed) and a conceptual limitation (there is no comparison to other classroom environments, for example). Collecting a larger, more diverse data set would help ameliorate both of these limitations in the future.

Future work that builds on these findings include using more sophisticated time-dependent models on a larger sample size that take full advantage of the data structure. Of course, this approach would involve very intensive data collection from multiple classrooms, so the practical challenges should not be ignored. These types of analysis might make it possible to evaluate how SI changes over time in a classroom as well as how each group assignment may have particularly impacted pre-to-post differences in conceptual knowledge and physics identity.

\section{ACKNOWLEDGMENTS}

We would like to thank the DBER group in the STEM Transformation Institute at FIU along with the students who participated in this study that made this research possible. 


\section{BIBLIOGRAPHY}

[1] Y. Xue and R. C. Larson, Mon. Labor Rev. 2015, (2015).

[2] E. Seymour and N. M. Hewitt, Talking about Leaving Revisited (Westview Press, Boulder, CO, 2019).

[3] S. Freeman, S. L. Eddy, M. McDonough, M. K. Smith, N. Okoroafor, H. Jordt, and M. P. Wenderoth, Proc. Natl. Acad. Sci. U. S. A. 111, 8410 (2014).

[4] Z. Hazari, G. Sonnert, P. M. Sadler, and M.-C. Shanahan, J. Res. Sci. Teach. 47, n/a (2010).

[5] G. Potvin and Z. Hazari, in Proc. Phys. Educ. Res. Conf. (PERC), Portland, OR (2013).

[6] C. Reports and T. D. Reports, UniServe Sci. News 13, 14 (1999).

[7] K. A. Smith, S. D. Sheppard, D. W. Johnson, and R. T. Johnson, J. Eng. Educ. 94, 87 (2005).

[8] E. Brewe, L. Kramer, and G. O’Brien, Am. J. Phys. 76, 1155 (2008).

[9] D. W. Johnson and R. T. Johnson, Educ. Res. 38, 365 (2009).

[10] S. M. Gully, D. J. Devine, and D. J. Whitney, Small Gr. Res. 26, 497 (1995).

[11] S. W. J. Kozlowski, S. M. Gully, E. R. Nason, and E. M. Smith, SIOP Front. Ser. 240 (1999).

[12] C. K. W. De Dreu, J. Appl. Psychol. 92, 628 (2007).

[13] R. K. Thornton and D. R. Sokoloff, Am. J. Phys. 66, 338 (1998).

[14] D. W. Johnson, A. Norem-Habeisen, and A. A. NoremHebeisen, J. Soc. Psychol. 109, 253 (1979).

[15] J. E. Driskell, E. Salas, and S. Hughes, Hum. Factors 52, 316 (2010).

[16] G. Van der Vegt, B. Emans, and E. Van de Vliert, Gr. Organ. Manag. 23, 124 (1998).

[17] J. A. Wagner, Acad. Manag. J. 38, 152 (1995).

[18] J. Honaker, G. King, and M. Blackwell, (2015).

[19] A. C. Choirat, J. Honaker, K. Imai, G. King, and O. Lau, Package 'Zelig ' (2016).

[20] P. Royston, Stata J. 5, 527 (2005).

[21] R. Wageman, Adm. Sci. Q. 40, 145 (1995).
[22] A. Godwin, G. Potvin, Z. Hazari, and R. Lock, J. Eng. Educ. 105, 312 (2016).

[23] J. Wang and Z. Hazari, Phys. Rev. Phys. Educ. Res. 14, 20111 (2018).

[24] V. Sawtelle, E. Brewe, and L. H. Kramer, J. Res. Sci. Teach. 49, 1096 (2012).

[25] L. Riebe, D. Roepen, B. Santarelli, and G. Marchioro, Educ. Train. 52, 528 (2010).

[26] K. Sheppard, P. Dominick, and Z. Aronson, Int. J. Eng. Educ. 20, 475 (2004).

[27] R. H. Moorman and G. L. Blakely, J. Organ. Behav. 16, 127 (1995).

[28] J. A. McCarty and L. J. Shrum, J. Public Policy Mark. 20, 93 (2001). 